\title{
Carcinoid syndrome
}

\section{Habib ur Rehman MBBS}

A 72-year-old man was admitted to hospital with congestive heart failure, weight loss and chronic diarrhea. He had flushing of the face and cyanosis, and telangiectasia were present in the cheek area (Figure 1).

A contrast-enhanced computed tomography scan of the liver showed multiple masses with ring enhancement that were compatible with metastases (Figure 2). An echocardiogram showed right-sided dilation of the heart with severe tricuspid regurgitation. The patient's aortic, mitral and pulmonic valves were normal in structure and function. A 24-hour urine collection showed a total output of 5-hydroxyindoleacetic acid of 1515 (normal 0-43) $\mu \mathrm{mol} / \mathrm{L}$. A biopsy of the liver with immunostaining for chromogranin and synaptophysin were strongly positive and confirmed a diagnosis of metastatic carcinoid syndrome. The patient died 4 months later.

A carcinoid tumour is a rare neuroendocrinologic malignancy that commonly originates from enterochromaffin cells in the gastrointestinal tract. The rate of incidence of carcinoid tumours has increased from 1.09 cases per 100000 in 1973 to 5.25 cases per 100000 in 2004, with a median age at diagnosis of 63 years. ${ }^{1}$ This increase has likely resulted from improvements in the classification of such tumours and from more widespread use of certain diagnostic screening tools such as endoscopy. Carcinoid syndrome occurs when cells from the tumour metastasize to the liver and vasoactive substances enter systemic circulation via the hepatic vein. Flushing involving the face and upper trunk are the most prominent cutaneous signs. Telangiectasias may also develop. Flushing may be worsened by the consumption of hot foods and beverages, chocolate, spicy foods, tomatoes, alcohol and cheeses or by emotional stress. $^{2}$ As many as $20 \%$ of patients with carcinoid syndrome present with carcinoid heart disease at diagnosis. Echocardiographic abnormalities, commonly involving the tricuspid valve, are found in up to $70 \%$ of patients. ${ }^{3,4}$ The median duration of survival is 124 months for patients with neuroendocrine tumours at the grade 1 stage, 64 months for those with grade 2 tumours and 10 months for those with grade 3 or 4 tumours.

\section{REFERENCES}

1. Yao JC, Hassan M, Phan A, et al. One hundred years after "carcinoid": epidemiology of and prognostic factors for neuroendocrine tumors in 35,825 cases in the United States. J Clin Oncol 2008;26:3063-72.

2. Sabir S, James WD, Schuchter LM. Cutaneous manifestations of cancer. Curr Opin Oncol 1999;11:139-44.

$\underset{\sim}{ \pm}$ 3. Bhattacharyya S, Davar J, Dreyfus G, et al. Carcinoid heart disease. Circulation 2007;116:2860-5.

4. Pellikka PA, Tajik AJ, Khandheria BK, et al. Carcinoid heart disease: clinical and echocardiographic spectrum in 74 patients. Circulation 1993;87:1188-96.

From the Department of Internal Medicine, Regina General Hospital, Regina Qu'Appelle Health Region, Regina, Sask.

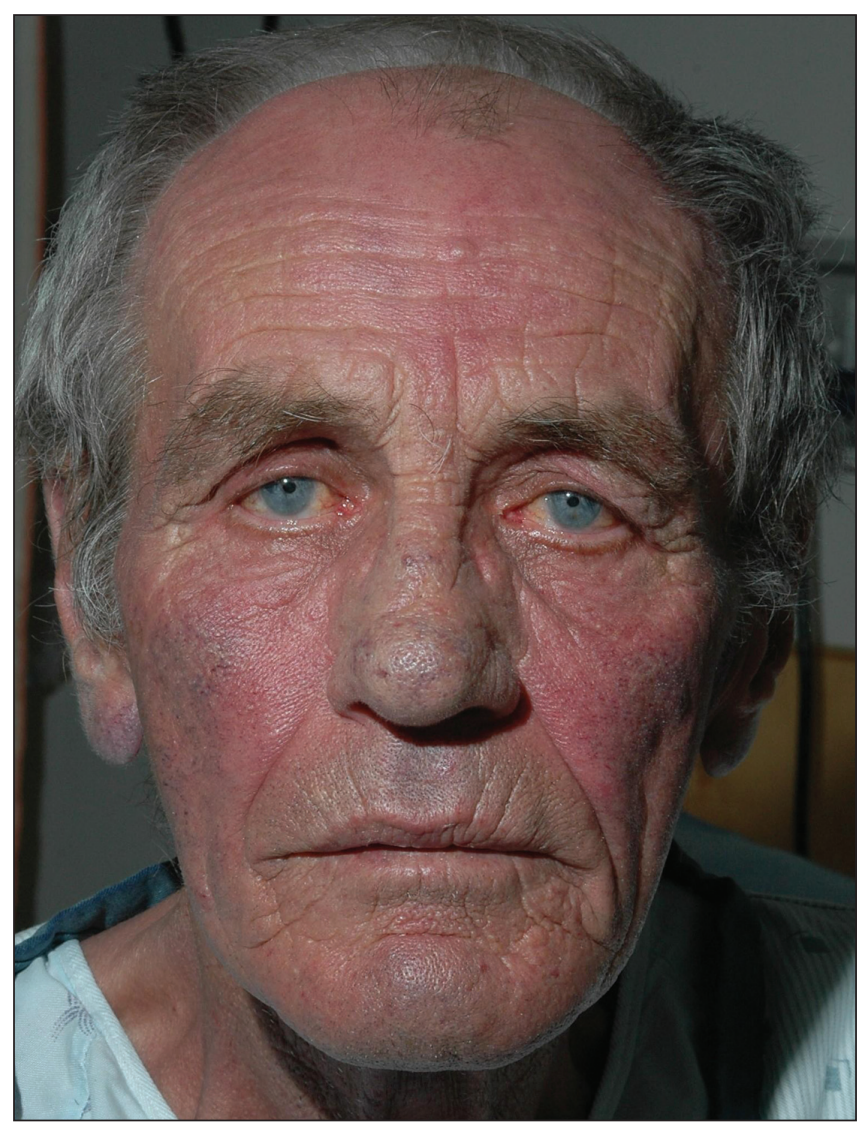

Figure 1: A 72-year-old man with carcinoid syndrome, showing flushing, cyanosis and telangiectasia.

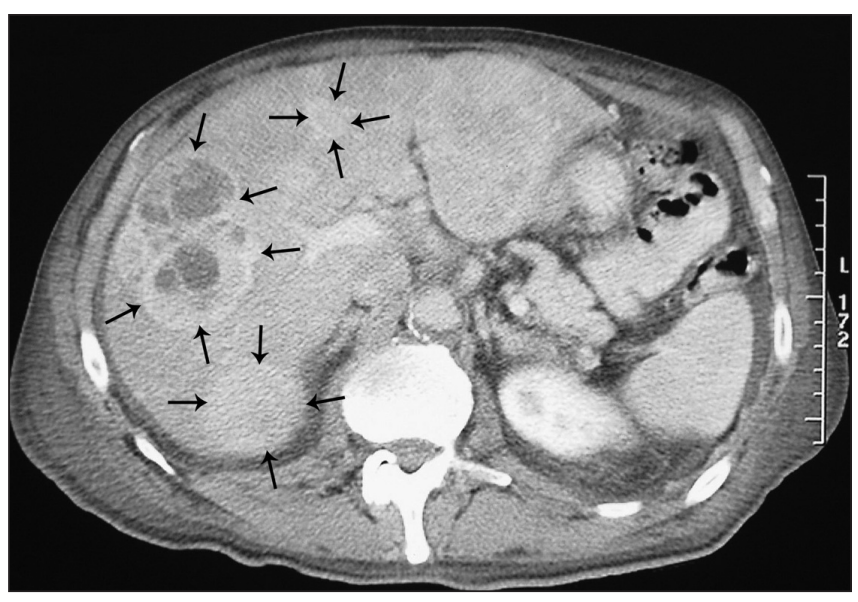

Figure 2: Contrast-enhanced computed tomography scan of the liver showing numerous masses compatible with metastases. 